\title{
Prevalence of Hypertension and Associated Factors among Bank Workers in Harar Town, Eastern Ethiopia 2018
}

Gosaye Teklehaymanot Zewde

Department of Midwifery, Harar Health Science College, Harar, Ethiopia.

Corresponding Author: Gosaye Teklehaymanot Zewde, (Rmw, Bsc Nurse, Msc in Maternity and Neonatal Nursing) Department of Midwifery, Harar Health Science College, Harar, Ethiopia.

Received date: August 12, 2020; Accepted date: September 11, 2020; Published date: September 16,2020

Citation: Zewde G T (2020) Prevalence of Hypertension and Associated Factors among Bank Workers in Harar Town, Eastern Ethiopia 2018.JGeneral Medicine and Clinical Practice. 3(2) DOI: 10.31579/2639-4162/029

Copyright: (C2020 Gosaye Teklehaymanot Zewde. This is an open-access article distributed under the terms of the Creative Commons Attribution License, which permits unrestricted use, distribution, and reproduction in any medium, provided the original author and source are credited.

\section{Abstract}

Background: Hypertension clinically defined as a blood pressure of 140/90 $\mathrm{mmHg}$ or more on at least two readings on separated time. It is one of the most prevalent non communicable diseases and the most important preventable risk factor for premature death worldwide, due to heart disease and stroke. It is the most important modifiable risk factor for coronary heart disease, stroke, congestive heart failure, end stage renal disease and peripheral vascular diseases

Objective: To assess the prevalence of hypertension and its associated factors among bank workers in Harar town, Eastern Ethiopia 2018

Methods and material: Institutions based cross sectional study was conducted on 149 Bank workers in 6 governmental and 19 private banks which were found in Harar Town. Sample was allocated proportionately and study participant was selected by simple random sampling. Collected and checked data were entered in to Epi Data software version 3.02 and exported and analyzed using SPSS version 21 . Descriptive statistics were used to determine prevalence such as frequency, percentage, mean and ratio. Both Bivariate and multiple logistic regressions were used to observe the association between the outcome variable and associated factors. P value less than 0.2 in Bivariate analysis was transferred to multivariate analysis and $\mathrm{P}$ value less than or equal to 0.05 was considered as level of statistically significance.

Result: The prevalence of hypertension on this study was $27.5 \%$. Among study participant $6(4 \%)$ had diagnosed with hypertension and only 3 $(2 \%)$ had on treatment and follow- up. 26(17.4\%) bank workers BMI Was obsessed. In multivariable logistic regression analysis Age, Sedentary life style and BMI of bank workers had significant association with hypertension

Conclusion and recommendation: The prevalence of Hypertension in the study was 27.5\% Age, Sedentary life style and BMI (Obesity) in this study was positively associated with higher odds of having hypertension. Regular blood monitoring, conducting physical exercise and reduction of Alcohol consumption and street Treatment care and follow-up strategy need to be maintained.

Key Word: hypertension; bank workers; harar town; blood pressure; prevalence; systolic; diastolic

\section{Introduction:}

Hypertension clinically defined as a blood pressure of $140 / 90 \mathrm{mmHg}$ or more on at least two readings on separated time. It is one of the leading causes of global burden of disease. It is being the root cause of many of the body system and organs failure remains to be a major public health challenge globally. [1] It is one of the most prevalent non communicable diseases and the most important preventable risk factor for premature death worldwide, due to heart disease and stroke [2] Hypertension is the most important modifiable risk factor for coronary heart disease, stroke, congestive heart failure, end stage renal disease and peripheral vascular diseases [3].

\section{Statement of the problem}

Globally, the overall prevalence of Hypertension in adults aged 25 and over was around $40 \%$ and was estimated to cause 7.5 million deaths, about $12.8 \%$ of the total of all deaths worldwide and the number of people with uncontrolled hypertension increased by $70 \%$ between 1980 and 2008 The rising epidemic of hypertension is thought to be due to mechanization, population growth and ageing [4, 5] By 2025 the number of hypertensive people is expected to increase by $60 \%$ and reach 1.56 billion people [6]. The prevalence of hypertension varies worldwide in Africa indicated the overall prevalence of hypertension have been increasing since 1990. In adults aged $\geq 20$ years, in 1990 the prevalence was $19.1 \%$, in 2000 prevalence were estimated $24.3 \%$,in 2010 with prevalence of $25.9 \%$ and it will projected to $25.3 \%$ by 2030 [7]. In sub-Saharan Africa estimated in 2008 was $13.7 \%$ in rural areas, $20.7 \%$ in urban area, $16.8 \%$ in males, and $15.7 \%$ in women [8]. The pooled prevalence of hypertension among the Ethiopian population was $19.6 \%$ and $20.6 \%$ in male and $19.2 \%$ in female. There is no sufficient data in the study area therefore this study was intended to provide compressive and up to date evidence on the prevalence and investigate the associated factors of Hypertension among Bank Workers of Harar town, Eastern Ethiopia.

Significance of the study: The study will describe the current situation of HPN in among bank workers in Harar town and it will be helpful for sampled population to know their BP status and for early linked to health institution to management if they have HTN. It will also 
be important for concerned bodies for prevention and management of hypertension. It will be serving as a base line data for others researchers.

\section{Objectives}

General objective: To assess the prevalence of hypertension and its associated factors among bank workers in Harar town, Eastern Ethiopia 2018

\section{Specific objective}

* To determine the prevalence of hypertension among Bank workers in Harar town, Eastern Ethiopia

* To identify factor associated with hypertension among Bank workers in Harar town, Eastern Ethiopia

\section{Methods}

Study area and period: The study was conduct in Harar town. Harari region is located in eastern part of Ethiopia, $525 \mathrm{~km}$ away from Adiss Abeba capital of Ethiopia. In the region there are 6 governmental and 19 private banks with a total of 25 branches was found. And the total numbers of bank workers was 313, of which 142 were found in governmental and the rest were found on private. The study was conducted from January 12-18/2018 G.C.

Study design: Institutional based cross-sectional descriptive study design was used

\section{Study population}

\section{Source population}

$>$ All Bank workers who are working in Harar town.

\section{Study population}

$>$ Selected Bank workers in Harar town who are alive on their work during data collection period

\section{Eligible criteria}

\section{Inclusion criteria}

$>$ Bank workers who are volunteer to participate will participate on the study.

\section{Exclusion criteria}

$>$ Bank workers who are not presented on their work during data collection period.

Sample size determination : Sample size was determined by using a single population proportion formula by assuming 5\% marginal error and $95 \%$ confidence interval $(\partial($ alpha $)=0.05)$ and prevalence of hypertension, which was $19.1 \%$ from study conducted in Addis Abeba [9] and the sample become 237. After calculating finite population correction formula and adding $10 \%$ non-response rate the final sample size will be come 149 .

Sample technique and procedure: Sample was allocated for each private and governmental Banks based on their number of workers. Simple random sampling was used to select study participants.

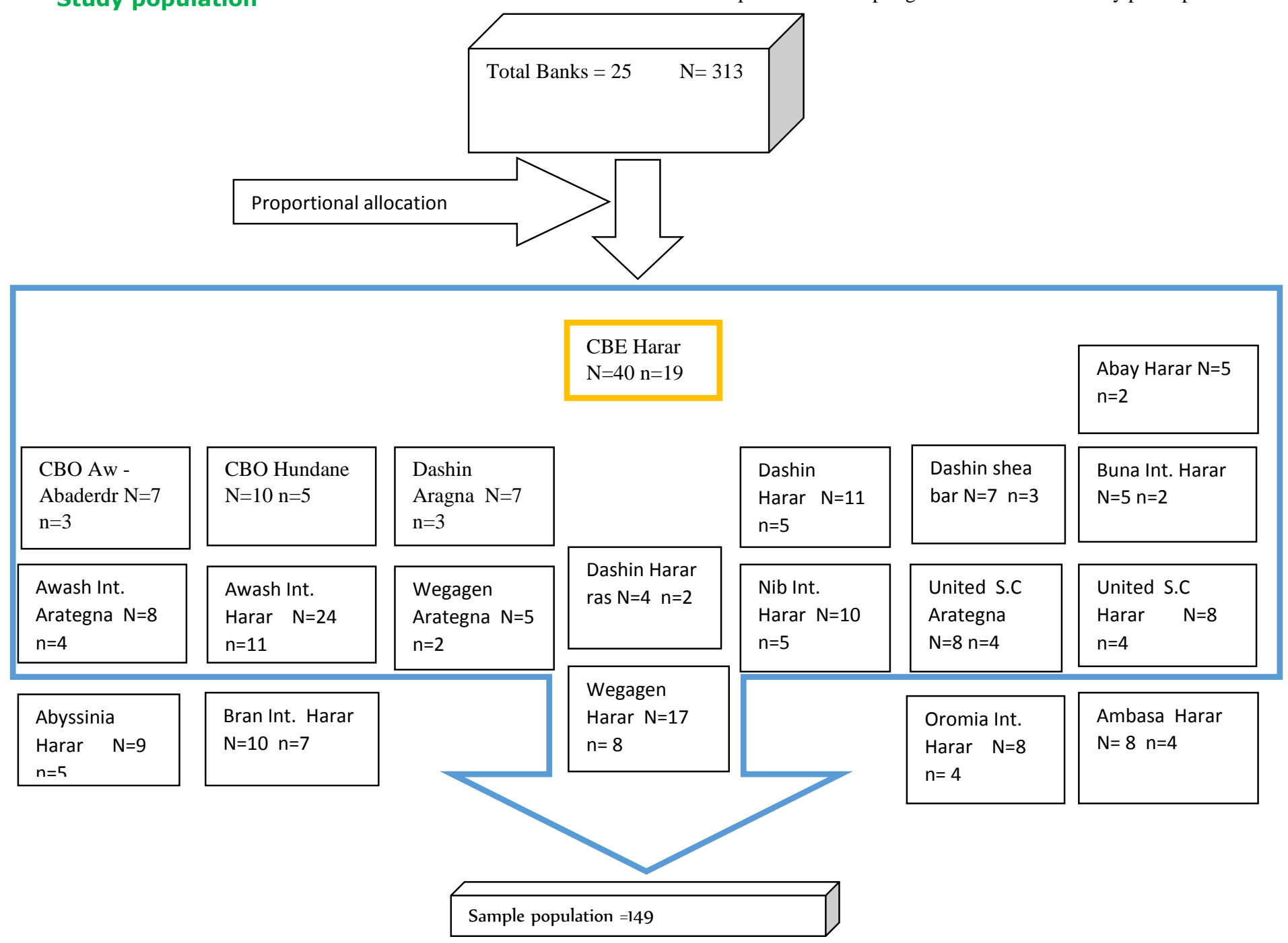

Figure 1: Schematic representation of sampling technique for sample selection among bank workers in Harar town, 2018 


\section{Variables}

Dependent variable: Hypertension status

\section{Independent variables}

Socio demographic Variable: Sex, Age, Marital status, Educational level, Job description

Medical history: Parental History of HTN, Previous History of HTN

Dietary and Behavioral Habit: Overweight, Obesity, Salt Consumption, Smoking, Excessive alcohol consumption

Work related risk factors: Sedentary lifestyle, Work schedule, and less physical activity.

\section{Data collection tolls and method:}

A semi- structure questioner was developed by English version after literature review and it was translated into local language and return back to English version to check its consistency. The questioner had 4 parts socio-demographic, Medical History, Hypertension risk assessment and measurements parts. Data was collected by face to face interview and objective data was selected through measuring height, weight, Blood pressure and BMI also calculated.

\section{Data Processing and Analysis:}

After data collection, data was cleaned, tabulated, rearranged and checked for its completeness and consistency and it was analyzed using SPSS version 21.0. The descriptive statistics was used to determine prevalence such as percentage, frequency and mean. Bivariate analysis was used first to determine the association between dependant and independent variable and multiple logistic regression analysis were used for better prediction of determinants and to reduce bias due to confounders. Variables with Pvalue less than 0.2 in bivariate analysis were entered in to multiple logistic regression analysis and $\mathrm{P}$ - value less than 0.05 was declared as statistically significant in the final model.

Data Quality Assurance: To assure the quality of the data, properly data collection instrument was developed and pretest on $10 \%$ of the total sample and amendment was done based on it. Questionnaires were translated into local language and training was given for data collector's supervisor and data entry clerks prior to the study. Every day, the collected data was reviewed for completeness, consistency and legibility. Supervision was frequently made by the supervisors and principal investigator

Ethical Considerations: Ethical clearance letter was obtained from Harar health Science College Institution Research Ethics Review Committee. Permission was obtained from study institution. All the participants were informed about the purpose, advantages and disadvantages, and there right to be involved or not as well as withdraw any time. Informed consent was obtained from all participants. Confidentiality was maintained by avoiding names and other personal identification.

\section{Operational definitions}

Sedentary life style: A type of life style with little or low physical activity, sitting or lying while reading, socializing etc or using mobile phone / computer for more than 4 hours per day. Low physical activity: is aerobic physical activity less than 10 minutes per day.

Normal work schedule: Participants who work within 8 hours per day.

Extra work schedule: Participants who work more than 8 hours per day.

Current daily cigarette smoking: is a person who smokes cigarette one or more days per week.

Obesity: $\mathrm{BMI}>30 \mathrm{~kg} / \mathrm{m}^{2}$ and overweight $-25-29.9 \mathrm{~kg} / \mathrm{m}^{2}$

Blood Pressure Measurement: Collecting of data by using mercury sphygmomanometer twice with ten minute difference from different hand while the participant was seated

\section{Result}

\section{Socio-demographic characteristics of the study participants}

A of total 149 workers from twenty five bank branches were participated in the study. Majority $90(60.4 \%)$ of study participants were female. The mean age of participants was $33.48 \pm 26.43$ years. Two thirds of them $(66.4 \%)$ were married while $51(34.2 \%)$ were single. Majority 115 $(77.2 \%)$ and $69(46.3 \%)$ of respondent was First degree holder and Customer service officer. Regarding service year 69 (46.3) of the study participant were served for less than 5 years. (Table 1 )

\begin{tabular}{|c|c|c|c|}
\hline Socio-demographic variable & Category & Frequency & Percent $(\%)$ \\
\hline \multirow[t]{2}{*}{ Sex } & Male & 90 & 60.4 \\
\hline & Female & 59 & 39.6 \\
\hline \multirow[t]{5}{*}{ Age } & $\leq 24$ years & 13 & 8.7 \\
\hline & 25-34years & 96 & 64.4 \\
\hline & 35- 44years & 31 & 20.8 \\
\hline & $45-54$ years & 7 & 4.7 \\
\hline & $\geq 55$ years & 2 & 1.3 \\
\hline \multirow[t]{4}{*}{ Marital status } & Single & 51 & 34.2 \\
\hline & Married & 96 & 64.4 \\
\hline & Divorced & 1 & 0.7 \\
\hline & Widowed & 1 & 0.7 \\
\hline \multirow[t]{3}{*}{ Educational level } & Diploma/level IV & 23 & 15.4 \\
\hline & First degree & 115 & 77.2 \\
\hline & second degree and above & 11 & 7.4 \\
\hline \multirow[t]{6}{*}{ Job description } & Manager & 18 & 12.1 \\
\hline & Auditor/Accountant & 15 & 10.1 \\
\hline & Relationship officer & 11 & 7.4 \\
\hline & Casher & 5 & 3.4 \\
\hline & Customer service officer & 69 & 46.3 \\
\hline & Others & 31 & 20.8 \\
\hline Working aria & Governmental & 68 & 45.6 \\
\hline
\end{tabular}




\begin{tabular}{|l|l|l|l|}
\hline & Non governmental & 81 & 54.4 \\
\hline \multirow{5}{*}{ Service years } & $<5$ years & \multicolumn{1}{|c|}{69} & 46.3 \\
\cline { 2 - 4 } & $5-10$ years & 65 & 43.6 \\
\cline { 2 - 4 } & $11-15$ years & 7 & 4.7 \\
\cline { 2 - 4 } & $16-20$ years & 4 & 2.7 \\
\cline { 2 - 4 } & $>20$ years & 4 & 2.7 \\
\hline
\end{tabular}

Table 1: Socio demographic characteristic of bank workers in Harar town, Eastern Ethiopia, January 12-18/2018

\section{Medical history of the study participants}

Among study participant $6(4 \%)$ was replied that they had diagnosed HTN in previous time and among those only 3 (2\%) started treatment and followup. While regarding their parents thirty eight (25.5\%) participant Biological parents had history of Hypertension and 95(63.8\%) was reported that their parents were Checked their BP previously (Fig 1)

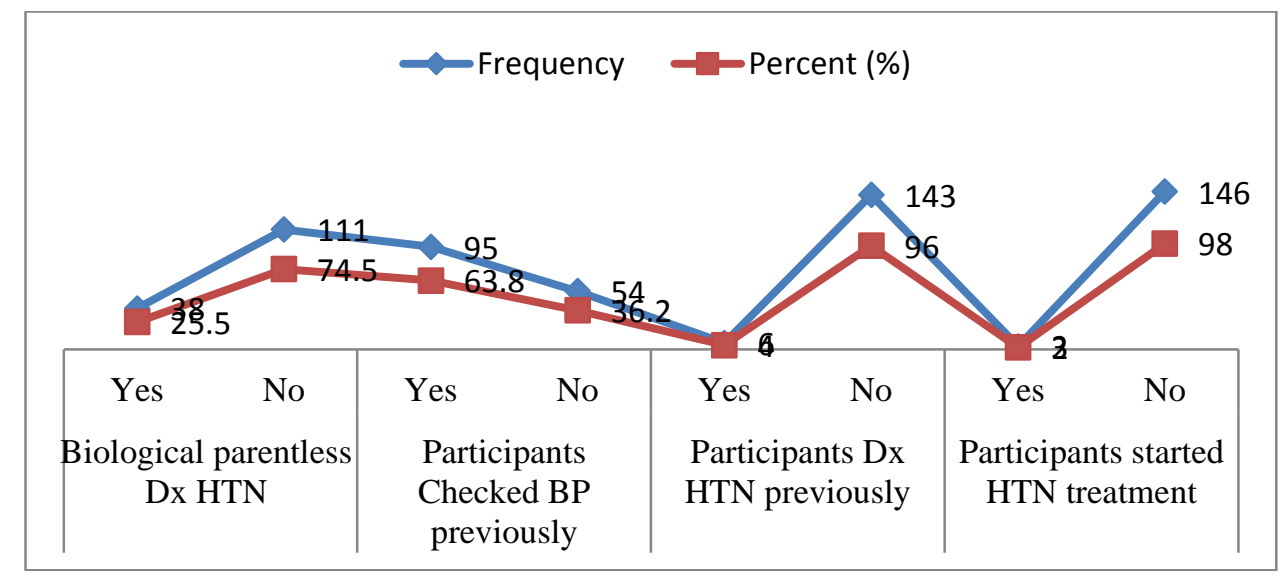

Fig 1: Medical History of bank workers in Harar town, Eastern Ethiopia, January 12-18/2018

\section{Behavioral and work related characteristic}

From total of participants responding, Forty nine (32.9\%) of participants drunk alcohol. Eight (5.4\%) were lifetime smokers. Majority of the participants $105(70.5 \%)$ used /added salt to food without tying. Ninety $(60.4 \%)$ of participant were involved in physical activity and $39(26.2 \%)$ stated that there was conduct exercise every day. (Table 2)

\begin{tabular}{|l|l|l|l|}
\hline Variables & Category & Frequency & Percent (\%) \\
\hline \multirow{2}{*}{ Drink alcohol } & Yes & 49 & 32.9 \\
\cline { 2 - 4 } & No & 100 & 67.1 \\
\hline \multirow{2}{*}{ Smoking } & Yes & 8 & 5.4 \\
\cline { 2 - 4 } & No & 141 & 94.6 \\
\hline \multirow{2}{*}{ Add salt to food without tying } & Yes & 105 & 70.5 \\
\cline { 2 - 4 } & No & 44 & 29.5 \\
\hline Physical exercise & Yes & 90 & 60.4 \\
\cline { 2 - 4 } & No & 59 & 39.6 \\
\hline Frequency of physical activities & all days of week & 39 & 26.2 \\
\cline { 2 - 4 } & $4-6$ days of week & 16 & 10.7 \\
\cline { 2 - 4 } & $1-3$ days of week & 35 & 23.5 \\
\hline \multirow{5}{*}{ Daily working time } & $<4$ hours & 11 & 7.4 \\
\cline { 2 - 4 } & $4-7$ hours & 15 & 10.1 \\
\cline { 2 - 4 } & exactly 8 hours & 37 & 24.8 \\
\cline { 2 - 3 } & $>8$ hours & 86 & 57.7 \\
\hline
\end{tabular}

Table 2: Behavioral and work related characteristic of bank workers of Harar town, Eastern Ethiopia, January 12-18/2018

\section{Anthropometric measurements of study participants}

Among the study subject, 74(49.7\%) participants had BMI $<25 \mathrm{~kg} / \mathrm{m}^{2}$ and 49(32.9\%) were overweight while $26(17.4 \%)$ were obesity. There mean and SD of BMI 25.41 4.546. Regarding BP Majority eighty three participants systolic blood pressure was $\leq 120 \mathrm{mmHg}$ and Diastolic Blood Pressure was $\leq 80 \mathrm{mmHg}$. There mean and SD of DBP was $81.13 \pm 11.231$.

Table 3: Anthropometric measurements characteristics of bank workers of Hara town, Eastern Ethiopia, January 12-18/2018 


\begin{tabular}{|l|l|l|l|}
\hline Anthropometric measurements & Category & Frequency & Percent $(\%)$ \\
\hline \multirow{4}{*}{ BMI } & $<18.5 \mathrm{~kg} / \mathrm{m} 2$ & 17 & 11.4 \\
\cline { 2 - 4 } & $18.5-24.9 \mathrm{~kg} / \mathrm{m} 2$ & 57 & 38.3 \\
\cline { 2 - 4 } & $25-29.9 \mathrm{~kg} / \mathrm{m} 2$ & 49 & 32.9 \\
\cline { 2 - 4 } & $>30 \mathrm{~kg} / \mathrm{m} 2$ & 26 & 17.4 \\
\hline \multirow{4}{*}{ SBP } & $\leq 120 \mathrm{mmHg}$ & 83 & 55.7 \\
\cline { 2 - 4 } & $121-139 \mathrm{mmHg}$ & 43 & 28.9 \\
\cline { 2 - 4 } & $\geq 140 \mathrm{mmHg}$ & 23 & 57.4 \\
\hline \multirow{3}{*}{ DBP } & $\leq 80 \mathrm{mmHg}$ & 86 & 15.5 \\
\cline { 2 - 4 } & $81-89 \mathrm{mmHg}$ & 34 & 22.8 \\
\cline { 2 - 4 } & $\geq 90 \mathrm{mmHg}$ & & \\
\end{tabular}

\section{Prevalence of Hypertension}

In this study the prevalence of hypertension was 41 (27.5\%) of which $6(4 \%)$ were previously diagnosed with having Hypertension and $35(23.5 \%)$ were newly diagnosed of Hypertension. Twenty six $(63.4 \%)$ of Hypertensive participant was male and 15 (36.6\%) were female. Majority 15(36.6\%) of Hypertensive bank workers' age was 25-34 years and $31(75.6 \%)$ was Married. Regarding working area $22(53.7 \%)$ had governmental and the rest $19(47.3 \%)$ were private bank employers. (Fig 2)

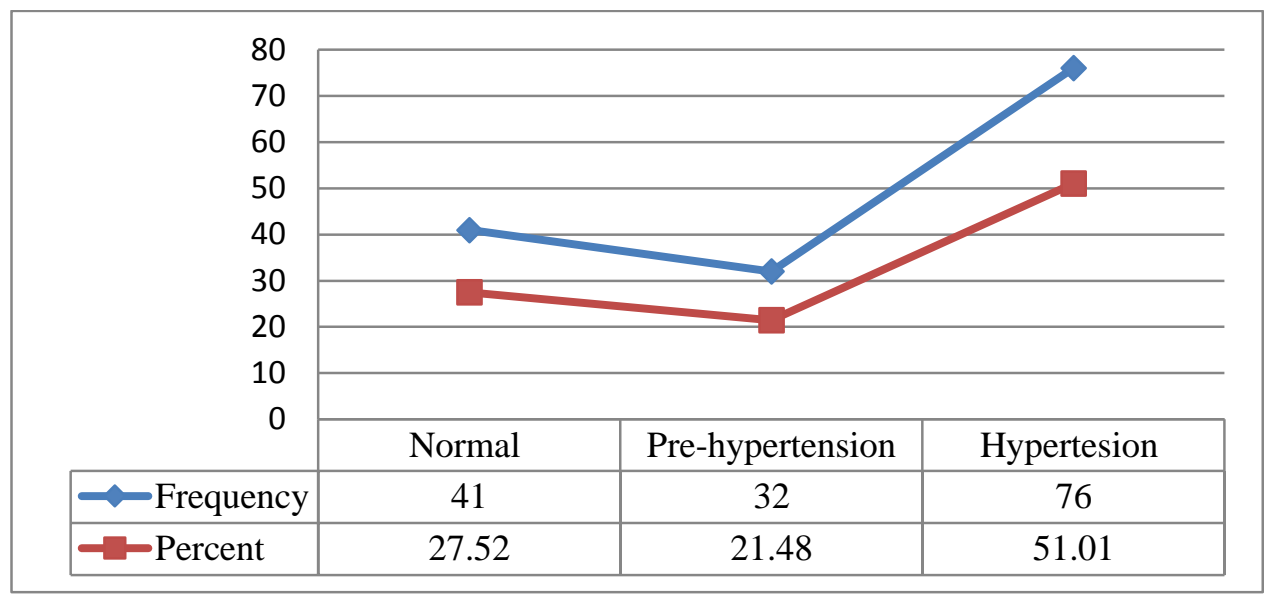

Fig 2: Hypertension status of of bank workers of Hara town, Eastern Ethiopia, January 12-18/2018

\section{Factors Associated with Hypertension:}

In multivariable logistic regression analysis Age, Sedentary life style and BMI of bank workers had significant association with hypertension. Bank workers whose age $25-44$ years had $75.8 \%$ (AOR=0.242, 95\% CI: 0.065

\begin{tabular}{|c|c|c|c|c|c|c|}
\hline \multirow[t]{2}{*}{ Characteristics } & \multicolumn{2}{|c|}{ Hypertension status } & \multirow[t]{2}{*}{ p-value } & \multirow[t]{2}{*}{ COR $(95 \% \mathrm{CI})$} & \multirow[t]{2}{*}{ p-value } & \multirow[t]{2}{*}{ AOR $(95 \% \mathrm{CI})$} \\
\hline & $\begin{array}{l}\text { Yes } \\
\text { No [\%] }\end{array}$ & $\begin{array}{l}\text { No } \\
\text { No [\%] }\end{array}$ & & & & \\
\hline \multicolumn{7}{|l|}{ AGE in years } \\
\hline$\leq 24$ & $5[12.2]$ & $8[7.4]$ & 0.005 & 1.00 & 0.008 & 1.00 \\
\hline $25-44$ & $2[68.3]$ & 99 [91.7] & 0.034 & $12.800[1.208-135.579]^{*}$ & 0.035 & $0.242[0.065-0.904]^{* *}$ \\
\hline$\geq 45$ & $8[19.5]$ & $1[0.9]$ & 0.002 & $28.286[3.393-235.832]^{*}$ & 0.292 & $4.042[0.300-54.420]$ \\
\hline \multicolumn{7}{|l|}{ Service in years } \\
\hline$\leq 10$ & $30[73.2]$ & $104[96.35]$ & .000 & 1.00 & & 1.00 \\
\hline$>10$ & $11[26.8]$ & $4[3.7]$ & .000 & $9.533[2.831-32.108]^{*}$ & 0.060 & $4.100[0.944-17.810]$ \\
\hline \multicolumn{7}{|c|}{ Sedentary life style } \\
\hline Yes & $32[78.0]$ & $60[55.6]$ & 0.014 & $2.844[1.239-6.531]^{*}$ & 0.034 & $2.925[1.085-7.885]^{* *}$ \\
\hline No & $9[22.0]$ & $48[44.4]$ & & 1.00 & & 1.00 \\
\hline \multicolumn{7}{|l|}{ BMI } \\
\hline Under weight & $2[4.9]$ & $15[13.9]$ & 0.002 & 1.00 & 0.023 & 1.00 \\
\hline Normal & $10[24.4]$ & $47[43.5]$ & 0.573 & $1.596[0.314-8.109]$ & 0.954 & $1.052[0.188-5.877]$ \\
\hline Overweight & $14[34.1]$ & $35[32.4]$ & 0.178 & $3.000[0.606-14.864]^{*}$ & 0.361 & $2.213[0.402-12.183]$ \\
\hline Obesity & $15[36.6]$ & $11[10.2]$ & 0.006 & $10.227[1.929-54.219]^{*}$ & 0.046 & $6.113[1.030-36.288]^{* *}$ \\
\hline
\end{tabular}

Table 4: Factors associated with Hypertension among bank workers of Harar town, Eastern Ethiopian, January, 2018

- 0.904) less likely had hypertension than age 24 years. Those who had sedentary life style had 3 times $(\mathrm{AOR}=2.925,95 \% \mathrm{CI}: 1.085-7.885)$ more likely, Obesities bank workers were 6 times more likely (AOR= $6.113,95 \%$ CI: $1.030-36.28$ ) having hypertension than their in counters. (Table 4) 


\section{Discussion}

In this study the prevalence of hypertension was, $27.5 \%$ the finding was greater than study done in Owerri Nigeria which was $12.4 \%$ [10] and Addis Ababa the prevalence was $19.1 \%$ [9]. This discrepancy may be due to different age category of participants as well as BMI and socio cultural variation. But the study outcome is less than the result of study done among bank workers in Surratt city of India which was 30.4\% [11] and Ghana $38 \%$ [12]. The difference occurred possibly due to different in socio demographic and socio-cultural as well as life style and mean value different in BMI.

The study found that age of bank workers was significantly associated with Hypertension. Those age $24-45$ were $75.8 \%$ less likely had hypertension than bank worker whose their age was less than 24 years. But study conducted in Adiss Abeba on federal ministry civil servants showed that increased age was identified as a factor for hypertension. Study participants older than 48 years were more likely to be hypertensive than those less than 27 years [13] and study of bank employees of Surratt city in India also showed that age $\geq 50$ years increase the risk of hypertension [11]. Even if the age associated to had hypertension there is different in association of age categories. The variance may be due to having more sedentary life style in our study.

In this study the risk of being hypertensive was 3 times more likely among bank workers who had sedentary life style this finding was in line with study conducted in Surratt city of India 2 times more likely [11] and Ghana Accra. This shows that sedentary life decrease energy expenditure and increase cholesterol level in blood vessel which directly related with Cardio vascular disease i.e. Hypertension .

BMI of bank workers significant association with Hypertension, in this study obese bank workers were 6 times more risked for hypertension this finding also in line with study conducted in Adiss abeba which is obese were 7.36 times more likely to be hypertensive and in Sullia Taluk, Karnataka also obesity was strongly associated with hypertension.[14].

\section{Conclusion and recommendation}

\section{Conclusion}

The prevalence of Hypertension in the study was $27.5 \%$ which shows the high prevalence of hypertension in the study population. As in many other developing countries hypertension is becoming a serious public health concern among working bankers in Harar town, Eastern Ethiopia. Age, Sedentary life style and BMI (Obesity) in this study was positively associated with higher odds of having hypertension. However Sex, Marital status, educational level, Job description, alcohol drinking, smoking, salt usage, physical activity and working schedule had not associated with hypertension.

\section{Recommendations}

- Regular blood monitoring should have to be maintain

- Sedentary life style need to be avoid among bank workers

- Regular physical exercise need to be conducted by all bank workers on daily based.

- Close monitoring of BMI and maintaining to normal value should have to be maintain
- Alcohol consumption reduction mechanism need to maintain through BCC

- $\quad$ Biological parent encouragement for close monitoring of their blood pressure by the bank worker should be encouraged as HPN is a known family associated disease.

- Treatment care and follow-up strategy for their workers need to be maintained by bank administrators.

\section{Reference}

1. Mulueta Molla . (2015) Systemic Review of prevalence and Associated Factors of Hypertantion in Ethiopia: Finyding the Evidence. Science Journal of Public Health. Vol.3,No. 4, pp. 514-519.

2. Kearney PM, Whelton M, Reynolds K, Muntner P, Whelton PK, He J. Global burden of hypertension: Analysis of worldwide data. Lancet 2005; 365:217-223.

3. Kasper L. Cardiovascular disorders. In: Harrison's Principles of internal medicine, 18th edition ( July, 2011)

4. Fuster V, Kelly BB, editors. (2010) promoting Cardiovascular Health in the Developing Worled: Acritical Chalenge to Achive Global Health. Washington (DC).

5. Cooper RS, Amoah AG. Mensah GA (2013) High blood pressure: the foundation for epedemic Cardiovascular diseases in African populations. Ethn Dis 13:S48-52. PMID: 13677414

6. WHO, Non communicable Diseases country Profiles. 2011, 20Avenue Appia, 1211 Geneva 27, Switzerland.

7. Davies A Estimating the prevalence and Awareness rates of Hypertantion in Africa: A Systemic Analysis. Plosone. 2014 9(8)

8. M. Twagirumukiza, D. De Bacquer, J. G. Kips, G. de Backer, R. V. Stichele, and L. M. van Bortel, "Current and projected prevalence of arterial hypertension in sub-Saharan Africa by sex, age and habitat: an estimate from population studies," Journal of Hypertension, vol. 29, no. 7, pp. 1243-1252, 2011.

9. G.Fikadu and S Lamma. (2016) socioeconomic status and Hypertansion among Teacher and Bankersin Addis Ababa, Ethiopia, Hindawi publishing Corporation International Journal of Hypertansion volume 2016.

10. Diwe et al. Hypertansion among bank workers in owerri, Nigeria,.International Journal of medicine and Biomedical Research.

11. Momin, M.H., Desai, V.K.,\& Kavishwar, A.B . (2012). Study of socio-demographic factors affecting prevalence of hypertansion among bank worker employees of surat City. Indian J public Health, 56, 44-54.

12. PRINCE E . M. DAITEY (10442372) ,Assessment of work related Hypertansion bank workron among bank workera Accra Jully, 2014.

13. Angaw et al. BMC Cardiovascular Disorders (2015) 15:76

14. Ismail,et al.: prevalence and risk factors of hypertansion among bank employees of sullia Tiluk,Karnataka 